\title{
Cough Syncope Mimicking Epilepsy in Asthmatic Children
}

\author{
Robert H. A. Haslam and Bruno Freigang
}

\begin{abstract}
Cough syncope is a more common complication of childhood asthma than formerly recognized. We report twelve children with typical cough syncope who were identified in a pediatric clinic over a period spanning seven years. The condition may be confused with epilepsy because of frequently associated brief clonic convulsive movements during the height of the cerebral anoxia. Cough syncope is readily distinguished from epilepsy by a thorough history. The management and prevention of cough syncope is directed at the aggressive control of bronchospasm in children with asthma.
\end{abstract}

RÉSUMÉ: Syncope-à-la-toux imitant une épilepsie chez des enfants asthmatiques La syncope-à-la-toux est une complication de l'asthme chez l'enfant plus fréquemment qu'on le pensait autrefois. Nous rapportons les cas de 12 enfants avec des syncopes-à-latoux et examinés dans une clinique pédiatrique sur une période de 7 ans et demi. Cette condition peut être méprise pour l'épilepsie car elle est fréquemment associée à des mouvements convulsifs cloniques courts au faîte de l'anoxie cérébrale. Une anamnèse complète en permet la différentiation facilement. Le traitement et la prévention de la syncope-à-la-toux dépend du contrôle agressif du brochospasme chez l'enfant asthmatique.

Can. J. Neurol. Sci. 1985; 12: $45-47$

Syncope may be defined as a brief loss of consciousness associated with transient hypotension, decreased cerebral blood flow and electroencephalographic changes during the attack. Although the condition is common in adults, syncope is rare in children, particularly under ten years of age. Loss of consciousness, which coincides with a paroxysm of coughing, is an unusual type of syncope uncommonly reported in children ${ }^{(1,2,3,4)}$. As the syncopal episode may be associated with clonic movements, the condition may be confused with epilepsy ${ }^{(5)}$. We report twelve children with typical cough syncope, many of whom had previously been managed as epileptics unresponsive to anticonvulsant drugs.

\section{Patient Data}

During a seven year period from 1977 to 1984, twelve asthmatic children with cough syncope were investigated. There were five females and seven males; the ages ranged from 1 to 16 years with a mean age of 7.2 years. The frequency of the attacks was variable from monthly to once daily for up to a week at a time. The episodes of cough syncope were more frequent when bronchospasm was evident and were particularly common during sleep. Five of the subjects had been treated with conventional antiepileptic drugs because of convulsive movements and urinary incontinence during the attack. All children had perennial asthma and exercise-induced bronchospasm. In seven of the subjects the asthma was often triggered by viral infections.

The study included a history, physical and neurological examination, pulmonary function testing, and allergy investigations including skin testing and blood histamine levels performed by cation exchange chromatography. Chest radiographs, electrocardiograms (EKG) and electroencephalograms (EEG) were performed on each patient.

\section{RESUlts}

Eleven of the subjects had inhalant allergies and six showed allergic symptoms to specific foods. Pulmonary function testing was completed on eight patients and all showed reversible obstructive lung disease. Chest radiographs, EKG's and EEG's performed during symptom-free periods were normal in all subjects. Serum histamine levels were determined on seven subjects as well as from age and sex-matched asthmatics without cough syncope and from a group of normal non-asthmatic children. No statistically significant difference in histamine levels could be determined between these groups.

Follow-up of the twelve children for a period of up to seven years (mean 3.8 years) showed a complete resolution of cough syncope in ten with aggressive asthma management and in only two children is syncope present during severe exacerbations of asthma. No patients have been maintained on anticonvulsants. 


\section{Discussion}

Syncope follows an alteration in brain metabolism, the consequence of decreased cerebral blood flow usually secondary to systemic hypotension. The brain depends upon a constant blood flow and autoregulation protective mechanisms maintain cerebral circulation and oxygenation in spite of wide fluctuations in the systemic blood pressure ${ }^{(6)}$. A decrease in blood flow to the brain initially affects the cerebral cortex which is exquisitely sensitive to alterations in the circulation. Ischemia in the region of the cerebral cortex produces a transient loss of consciousness. If the hypoxemia persists, the hypothalamus and midbrain are affected. With increasing ischemia, the higher cortical centres release their inhibiting influence upon the reticular formation within the brainstem. Subsequently, neuronal discharges from the reticular formation produce brief tonic contractions of the axial muscles and associated clonic movements of the face, trunk and extremities ${ }^{(7)}$. Epileptic movements, in contrast, result from seizure discharges from the cerebral cortex and can readily be recorded on an EEG during a convulsion.

During a syncopal episode, the patient may have fixed upward deviation of the eyes which is not to be confused with epilepsy. The EEG shows transient slowing during the attack, but no seizure discharges. Although "typical" syncopal attacks presumably related to vaso-vagal stimulation and precipitated by pain, fear, excitement or immobilization while standing do occur in children, organic causes, including congenital heart disease (tetralogy of Fallot), aortic stenosis, conduction defects of the heart, hypoglycemia, severe anemia, and of course, episodes of coughing should be sought in this group of patients ${ }^{(8)}$. Some forms of epilepsy, particularly complex partial seizures, may present with a blank facial expression and gradual loss of consciousness similar to syncope.

Syncope related to cough is quite characteristic. It often occurs shortly after falling asleep and abruptly awakens the child. Asthmatic children have a marked diurnal variation of forced expiratory volume $\left(F E V_{1}\right)$ which accounts for the frequency of nocturnal cough syncope in these children. The paroxysm of coughing although forceful and severe usually persists for only a brief period. The child's face initially becomes very red and perspiration is evident. The patient is extremely agitated and frightened. Loss of consciousness is associated with generalized muscle flaccidity, vertical upward gaze and clonic muscle contractions lasting several seconds may be observed. Urinary incontinence is frequent. Within seconds recovery begins and consciousness is usually complete minutes later. The child has no recollection of the attack except for the events surrounding the paroxysm of coughing.

Several mechanisms have been proposed to explain the pathophysiology of cough syncope. Studies have suggested a concussive phenomenon due to the high intracranial pressures produced by the cough $^{(1)}$, an unusal laryngeal reflex ${ }^{(9)}$, an epileptic "equivalent" (10), and a circulatory disturbance resulting from excessive peripheral vasodilation ${ }^{(11)}$, or decreased cardiac output due to reduced inflow or marked pulmonary vasoconstriction $^{(12)}$. The prevailing theory suggests that with the coughing attack there is a marked increase in intrapleural pressure followed by a lowered venous return to the right side of the heart and a concomitant decrease in right ventricular output. The above events lead to a decrease in left ventricular filling and a diminished cardiac output resulting in an alteration of the cerebral blood flow, cerebral hypoxia and loss of consciousness ${ }^{(11,13)}$. Why some children have significant cerebral hypoxia with a paroxysm of coughing and others do not remains unknown, but probably relates to the duration of the paroxysms, the mean intrathoracic pressure during the coughing episode, state of hydration and vascular stability and the $\mathrm{PO}_{2}$ at the onset of the paroxysm.

Cough syncope should not be confused with epilepsy (Table 1). It always is associated with a coughing paroxysm, the face becomes plethoric rather than cyanotic and the entire episode lasts less than a minute. Cough syncope usually occurs at night while prone whereas epilepsy can develop in any position. Most older children with cough syncope can recall the tussive episode prior to the loss of consciousness whereas a convulsion is heralded by sudden unconsciousness occasionally with abdominal discomfort, visual or auditory auras. The convulsive movements are usually more prominent and persistent in epilepsy. Cough syncope is usually associated with brief loss of consciousness, lack of postictal confusion and headache, a normal interictal EEG and unresponsiveness to anticonvulsant medication which further distinguishes it from epilepsy. The cornerstone of management for asthmatic children with cough syncope is an aggressive approach to all parameters of broncho-constriction prevention $^{(14)}$.

\section{ACKNOWLEDGEMENTS}

The authors are grateful to Dr. William Whitelaw for helpful suggestions and to Elizabeth McRobbie for manuscript preparation.

Table 1: Characteristics which distinguish Cough Syncope from Epilepsy

\begin{tabular}{l|l|l}
\hline \hline & COUGH SYNCOPE & TONIC-CLONIC SEIZURE \\
\hline Asthma with cough paroxysm & Always & Never \\
\hline Aura & Never & Occasional \\
\hline Color & Plethoric facies & Cyanotic \\
\hline Duration of tonic-clonic movements & Brief & May be prolonged \\
\hline Post-ictal confusion/headache & Very rare & Frequent \\
\hline Response to anticonvulsants & None & Good \\
\hline EEG & $\begin{array}{l}\text { Generalized slow during episode } \\
\text { Normal interictal }\end{array}$ & $\begin{array}{l}\text { Seizure discharges during and interictally are } \\
\text { frequent }\end{array}$ \\
\hline \hline
\end{tabular}




\section{REFERENCES}

1. Kerr A Jr, Eich RH (1961) Cerebral concussion as a cause of cough syncope. Arch. Intern. Med. 108: 248-252.

2. Blue JA (1968) Syncope in allergy. Ann. Allergy 26: 561-568.

3. Katz RM (1970) Cough syncope in children with asthma. J. Pediatr. 77: $48-51$.

4. Jain AM (1971) Cough syncope. Indian J. Pediatr. 38: 434-436.

5. Charcot JM (1876) Statement to the Societé de Biologie. Gaz. Med. Paris 5: 588.

6. Engel GL (1962) Fainting ( 2 ed). Charles C. Thomas, Springfield, III.

7. Lee RG, Becker WJ (1983) Neurologic disorders. In C.A. Guenter. Internal Medicine. Churchill Livingstone, New York pp. 500-503.

8. Wright FS (1982) Recurrent paroxysmal nonepileptic disorders. In: K.F. Swaiman and F.S. Wright (2nd ed). The Practice of Pediatric Neurology. The C.V. Mosby Co., St. Louis. pp. 1076-1077.
9. Getchell AC (1896) A contribution on the study of laryngeal vertigo. Boston Med. Surg. J. 135: 466.

10. O'Doherty DS (1953) Tussive syncope and its relation to epilepsy. Neurology 3: 16-21.

11. Sharpey-Schafer EP (1953) The mechanism of syncope after coughing. Br. Med. J. 2: 860-863.

12. McCann WS, Bruce RA, Lovejoy FW, Yu PNG, Pearson R, Emerson EB, Engle G, Kelly JJ (1949) Tussive syncope. Arch. Intern. Med. 84: 845-856.

13. Pedersen A, Sandoe E, Hvidberg E, Schwartz M (1966) Studies on the mechanism of tussive syncope. Acta. Med. Scand. 179: 653-661.

14. Dolovich J, Hargreave FE, Wilson WM, Greenbaum J, Powles AC, Newhouse MT, (1982) Control of asthma. Can. Med. Assoc. J. 126: 613-618. 